\title{
Relación entre el estado nutricional y la cronología de la erupción dental en estudiantes escolares de Tacna
}

\section{Relationship of the nutritional state with the chronology of dental eruption in school students in Tacna}

\author{
Noelia Yésica Martínez Cántaro ${ }^{1 a}$ \\ ${ }^{1}$ Escuela Profesional de Odontología de la Universidad Nacional Jorge Basadre Grohmann. Tacna, Perú. \\ ${ }^{b}$ Docente, Maestro en Odontología con mención en Patología.
}

\section{Resumen}

Objetivo: Determinar la relación del estado nutricional con la cronología de la erupción en estudiantes de 6-12 años de la Institución Educativa Nacional Gregorio Albarracín de Tacna en el año 2017. Materiales y métodos: Este estudio es de tipo prospectivo, observacional, de corte transversal y nivel descriptivo relacional. La técnica realizada fue la observación clínica. Por un lado, se obtuvo el índice de masa corporal mediante una ficha documental donde se registró el peso y la talla. Por otro lado, se realizó una evaluación intra-oral en donde se observó la ausencia o presencia de piezas dentales. La muestra estuvo conformada por 177 niños. Resultados: Mediante la prueba estadística del chi cuadrado, se encontró que un $57.6 \%$ de los participantes eran obesos y un $42.4 \%$ se encontraban con normopeso. La erupción dentaria en la arcada superior ocurrió de la siguiente forma: primer molar (6.5 años) incisivo central (6.67 años), incisivo lateral (7.75 años), primer premolar (9.31 años), segundo premolar (9.83), canino (10.46 años) y segundo molar (11.6 años). En la arcada inferior ocurrió de la siguiente manera: incisivo central (6 años), incisivo lateral (6.42 años), primer molar (7 años), primer premolar (9.67 años), canino (9.8 años), segundo premolar y segundo molar (10.3 años). Conclusión: Se encontró relación entre el estado nutricional y la cronología en el primer molar, incisivo lateral y primer premolar inferior en niños de 8,9 y 10 años que presentaron obesidad. Existe relación entre el estado nutricional y la cronología de erupción; además, existe un adelanto de la erupción dentaria en la población estudiada.

Palabras clave: Cronología de la erupción, estado nutricional, niños.

\begin{abstract}
Objective: To determine the relationship of nutritional status with the chronology of the eruption in 6-12 year old students at Gregorio Albarracín public school in Tacna in 2017. Materials and methods: This is a prospective, observational and cross sectional study, as well as relational descriptive level study. The technique performed was clinical observation. On the one hand, the body mass index was obtained through a documentary record where weight and height were recorded. On the other hand, an intra-oral evaluation was performed where the absence or precense of dental pieces were observed. The sample consisted of 177 children. Results: Using the statistical chisquare test, it was found that $57.6 \%$ of the participants were obese and $42.4 \%$ had normoweight. The dental eruption in the upper arch occurred as follows: first molar (6.5 years) central incisor (6.67 years), lateral incisor ( 7.75 years), first premolar (9.31 years), second premolar (9.83), canine (10.46 years) and second molar (11.6 years). In the lower arch, it occurred as follows: central incisor (6 years), lateral incisor (6.42 years), first molar ( 7 years), first premolar ( 9.67 years), canine (9.8 years), second premolar and second molar (10.3 years). Conclusion: A relationship was found between the nutritional status and the chronology in the first molar, lateral incisor and first lower premolar in children aged 8,9 and 10 years who presented obesity. There is a relationship between nutritional status and eruption chronology; and also, there is an advance of the dental eruption in the population studied.
\end{abstract}

Keywords: Chronology of dental eruption, nutritional status, children. 


\section{Introducción}

El estado nutricional es la condición del individuo el cual resulta de la asociación entre las necesidades alimenticias y la ingestión, absorción y utilización de nutrientes contenidos en los alimentos. El buen estado nutricional permite al ser humano un buen desarrollo físico y psicológico. Asimismo, existe una valoración nutricional mediante una clasificación de acuerdo a una tabla dada por el Instituto Nacional de Salud y el Centro Nacional de Alimentación y Nutrición (1).

La obesidad es el resultado de un desequilibrio entre el gasto energético y la ingesta calórica que resulta en la acumulación de exceso de grasa donde el $54.8 \%$ de la ingesta total de calorías proviene de los carbohidratos. Además, una gran proporción de niños obesos se convierten en adultos obesos $(2,3)$.

Según la Organización Panamericana de la Salud (OPS), el Perú ocupa el octavo lugar en el ranking mundial de obesidad infantil junto a países como Chile y México. Se menciona además que los niños de seis a nueve años son los más afectados.

Una alteración a nivel óseo con cierto grado de adiposidad puede aumentar la densidad de hueso vertebral, el tamaño de hueso, así como la aceleración del crecimiento esquelético (4-6).

Por lo general los factores locales están asociados al retraso de la erupción en la dentición permanente (7-9). Factores como el estado nutricional, sexo, la raza, la herencia, el ambiente y el nivel socioeconómico pueden influir adelantando o retrasando la secuencia y tiempo de erupción $(10,11)$.

Si la maduración dental está comandada por los mismos factores que rigen el comportamiento del crecimiento óseo, podría ocurrir que los niños con edad ósea aumentada, producto de la obesidad, presenten también maduración dental aumentada (12). Es imposible establecer una edad determinada de aparición en la cavidad bucal (13). Sin embargo, muchos estudios han demostrado la influencia del estado nutricional sobre los estadíos de maduración esquelética (14).

En un estudio sobre la "Influencia del estado nutricional en la erupción dentaria permanente en estudiantes del nivel primario del Distrito de Ciudad Nueva-Tacna, 2012.", Flores (15) concluyó que existe retraso en la erupción dentaria del incisivo central superior $(p=0.021)$ en aquellos niños con obesidad y desnutrición; del mismo modo, se evidenció un retraso en la erupción del primer premolar inferior $(\mathrm{p}=0.01)$ en aquellos niños que presentaron desnutrición.

Algunos autores como Kelly K. Hilgers et al. (16) investigaron "La obesidad infantil y desarrollo dental en niños de 8 a 15 años". El referido estudio tuvo como objetivo saber si el aumento del índice de masa corporal estaba asociado con el desarrollo dental acelerado en niños de 8 a 15 años. La investigación demostró que el desarrollo dental se aceleró significativamente con el aumento del IMC.

Paredes Obando (17) en su estudio titulado "Estado nutricional actual y erupción dentaria de los incisivos permanentes en alumnos de 6 a 9 años de la I.E.P.S.M. 61004 del Distrito de Iquitos, 2014" concluyó que existe retraso en la erupción dentaria del incisivo central superior en aquellos alumnos con sobrepeso y riesgo de desnutrición; además, se evidenció un retraso en la erupción del incisivo central inferior en aquellos alumnos que presentaron riesgo de desnutrición.

La erupción dentaria es un proceso muy largo, lento y de características variables $(18,19)$. Las alteraciones cronológicas de erupción de la dentición temporal y permanente pueden tener como consecuencia graves problemas de maloclusión dental, esqueléticos, funcionales y estéticas; esto complica el diagnóstico y el tratamiento ortodóncico. La relación del estado nutricional y la cronología de erupción dentaria representan un aspecto valioso a investigar, especialmente en una población de niños menores de 12 años.

\section{Material y métodos}

Este estudio es de tipo prospectivo y observacional, de corte transversal y nivel descriptivo relacional. La población cuántica fue de 656 alumnos, de esta población se seleccionó una muestra de 177 estudiantes según criterios de inclusión y exclusión. La técnica realizada fue la observación clínica y se empleó como instrumento una ficha documental, previamente validada. Las medidas antropométricas usadas fueron el peso y la talla (20). Primero, se realizó una evaluación antropométrica donde se registró la talla y se obtuvo el peso mediante una báscula calibrada para pesar personas de pie; de esa forma, recabó el índice de masa corporal (IMC). Segundo, en cuanto a la evaluación intra-oral, se revisó la dentadura iniciándose por el cuadrante superior derecho continuando en sentido de las agujas del reloj, abarcando todos los cuadrantes, con la luz natural y con ayuda de un espejo bucal. Aquí, se pudo observar la ausencia o presencia de las piezas dentales indicadas en el estudio.

Para el procesamiento de datos se utilizó el software SPSS en su versión número 20 y la hoja de cálculo excel. Para el contraste de hipótesis, se aplicó la prueba de Chi cuadrado de Pearson a fin de relacionar ambas variables.

\section{Resultados}

La Gráfica 1 representa la distribución de los porcentajes en referencia al estado nutricional en la población de estudio con respecto a la edad, se observa que predomina un $71.1 \%$ de niños de 10 años con obesidad, seguido de un $70.8 \%$ y $61.3 \%$ de obesidad en niños de 8 y 9 años respectivamente; además, se encontró que un $58.3 \%$ de niños de 6 años presenta un estado nutricional normal, datos que van en aumento conforme la edad progresa. 


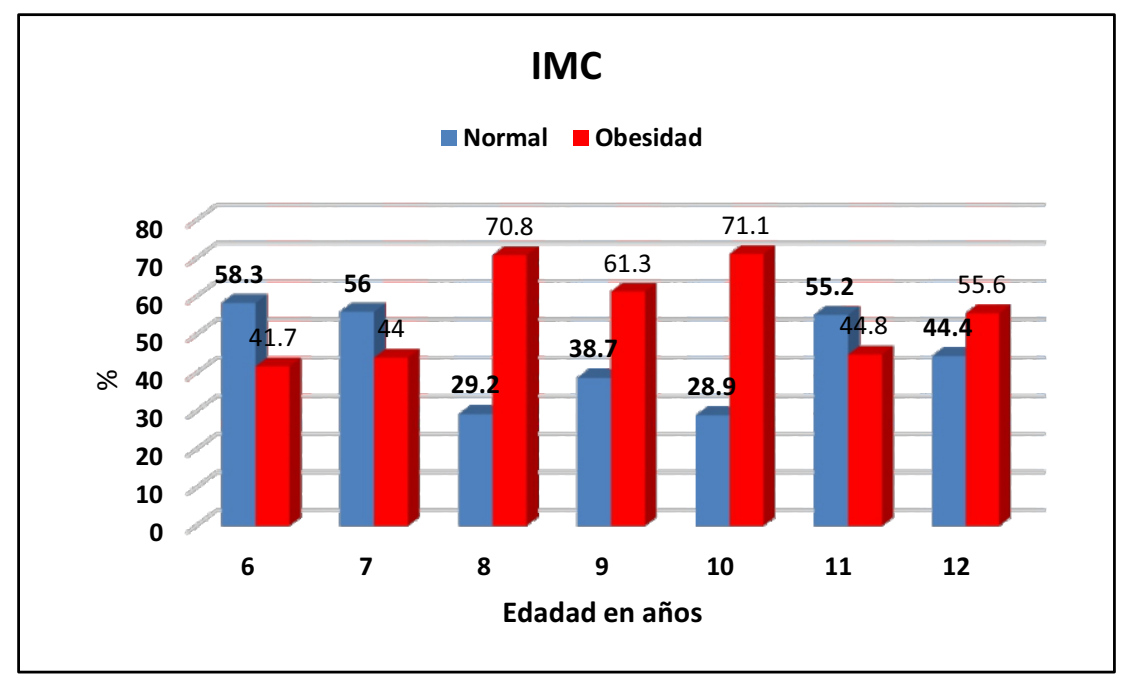

Gráfico 1. Distribución de frecuencia y porcentual del estado nutricional por edad de la población de estudio. Fuente: Matriz de sistematización (E.P).

La Tabla 1 presenta el inicio de erupción de las piezas dentarias de la arcada superior, hallándose los siguiente: primer molar (6.5 años) incisivo central (6.67 años), incisivo lateral (7.75, años), primer premolar $(9.31$ años), segundo premolar (9.83), canino (10.46 años) y segundo molar (11.6 años). En el caso de la arcada inferior, incisivo central ( 6 años), incisivo lateral (6.42 años), primer molar (7 años), primer premolar ( 9.67 años), canino (9,8 años), segundo premolar y segundo molar(10.3 años).

\section{Tabla 1. Cronología de la erupción en los estudiantes de 6-12 años de la Institución Educativa Nacional Gregorio Albarracín de Tacna, 2017}

$\begin{array}{lllll}\text { Arcada superior } & \text { Min } & \text { Media } & \text { Max } & \text { Desviación estándar } \\ \text { IC } & 6 & 6.67 & 7 & 0.47 \\ \text { IL } & 7 & 7.75 & 8 & 0.43 \\ \text { C } & 9 & 10.46 & 12 & 1.08 \\ \text { IPM } & 7 & 9.31 & 11 & 0.91 \\ \text { 2PM } & 6 & 9.83 & 12 & 1.30 \\ \text { IM } & 6 & 6.5 & 7 & 0.5 \\ \text { 2M } & 10 & 11.6 & 12 & 0.66 \\ & & & & \\ \text { Arcada inferior } & \text { Min } & \text { Media } & \text { Max } & \text { Desviación estándar } \\ \text { IC } & 6 & 6 & 6 & 0 \\ \text { IL } & 6 & 6.42 & 7 & 0.49 \\ \text { C } & 8 & 9.8 & 11 & 0.96 \\ \text { IPM } & 7 & 9.67 & 12 & 1.41 \\ \text { 2PM } & 9 & 10.3 & 12 & 0.70 \\ \text { IM } & 7 & 7 & 7 & 0 \\ \text { 2M } & 10 & 10.3 & 12 & 0.61\end{array}$

Fuente: Matriz de sistematización(E.P).

La Tabla 2 muestra que los niños de 8 años con obesidad evidencian erupción completa del incisivo central con un $88.2 \%$ en comparación a los niños con normopeso quienes en un $100 \%$ presentan una erupción completa del incisivo central. Cabe mencionar que el primer molar tiene una erupción completa con un 94.1 $\%$ en obesos y $71.4 \%$ en niños con estado nutricional normal, lo cual evidencia que existe asociación significativa entre el estado nutricional de los niños y la erupción del primer molar permanente. En las demás piezas dentarias no se observaron diferencias significativas y no se evidenció asociación entre el estado nutricional y la erupción dentaria $(\mathrm{p}>0.05)$. 
Tabla 2. Relación del estado nutricional en la cronología de la erupción de la arcada inferior en estudiantes de 8 años de la Institución Educativa Nacional Gregorio Albarracín de Tacna 2017

\begin{tabular}{|c|c|c|c|c|c|c|c|c|c|c|c|}
\hline \multirow{2}{*}{$\begin{array}{l}\text { Pza. } \\
\text { Dentaria }\end{array}$} & \multirow[t]{2}{*}{ IMC } & \multicolumn{2}{|c|}{ N.E } & \multicolumn{2}{|c|}{ I.E } & \multicolumn{2}{|c|}{ E.I } & \multicolumn{2}{|c|}{ E.C } & \multicolumn{2}{|c|}{ Total } \\
\hline & & $\mathrm{n}$ & $\%$ & $\mathrm{n}$ & $\%$ & $\mathrm{n}$ & $\%$ & $\mathrm{n}$ & $\%$ & $\mathrm{n}$ & $\%$ \\
\hline \multirow{4}{*}{$\begin{array}{l}\text { Incisivo } \\
\text { Central } \\
\mathrm{P}=0.407\end{array}$} & $\mathrm{~N}$ & 0 & $0.0 \%$ & 0 & $0.0 \%$ & 0 & $0.0 \%$ & 1 & $100.0 \%$ & 1 & $100.0 \%$ \\
\hline & & & & & & & & 4 & & 4 & \\
\hline & $\mathrm{O}$ & 1 & $2.9 \%$ & 0 & $0.0 \%$ & 3 & $8.8 \%$ & $\begin{array}{l}3 \\
0\end{array}$ & $88.2 \%$ & $\begin{array}{l}3 \\
4\end{array}$ & $100.0 \%$ \\
\hline & $\mathrm{D}$ & 0 & $0.0 \%$ & 0 & $0.0 \%$ & 0 & $0.0 \%$ & 0 & $0.0 \%$ & 0 & $100.0 \%$ \\
\hline \multirow{4}{*}{$\begin{array}{l}\text { Incisivo } \\
\text { Lateral } \\
\mathrm{P}=0.728\end{array}$} & $\mathrm{~N}$ & 4 & $28.6 \%$ & 0 & $0.0 \%$ & 4 & $28.6 \%$ & 6 & $42.9 \%$ & 1 & $100.0 \%$ \\
\hline & & & & & & & & & & 4 & \\
\hline & $\mathrm{O}$ & 7 & $20.6 \%$ & 2 & $5.9 \%$ & 8 & $23.5 \%$ & $\begin{array}{l}1 \\
7\end{array}$ & $50.0 \%$ & $\begin{array}{l}3 \\
4\end{array}$ & $100.0 \%$ \\
\hline & $\mathrm{D}$ & 0 & $0.0 \%$ & 0 & $0.0 \%$ & 0 & $0.0 \%$ & 0 & $0.0 \%$ & 0 & $100.0 \%$ \\
\hline \multirow{3}{*}{$\begin{array}{l}\text { Primer } \\
\text { Premolar } \\
\mathrm{P}=0.517\end{array}$} & $\mathrm{~N}$ & 14 & $100.0 \%$ & 0 & $0.0 \%$ & 0 & $0.0 \%$ & 0 & $0.0 \%$ & 14 & $100.0 \%$ \\
\hline & $\mathrm{O}$ & 33 & $97.1 \%$ & 1 & $2.9 \%$ & 0 & $0.0 \%$ & 0 & $0.0 \%$ & 34 & $100.0 \%$ \\
\hline & $\mathrm{D}$ & 0 & $0.0 \%$ & 0 & $0.0 \%$ & 0 & $0.0 \%$ & 0 & $0.0 \%$ & 0 & $100.0 \%$ \\
\hline \multirow{5}{*}{$\begin{array}{l}\text { Primer } \\
\text { Molar } \\
\mathrm{P}=0.048\end{array}$} & $\mathrm{~N}$ & 2 & $14.3 \%$ & 2 & $14.3 \%$ & 0 & $0.0 \%$ & 1 & $71.4 \%$ & 1 & $100.0 \%$ \\
\hline & & & & & & & & 0 & & 4 & \\
\hline & $\mathrm{O}$ & 1 & $2.9 \%$ & 0 & $0.0 \%$ & 1 & $2.9 \%$ & 3 & $94.1 \%$ & 3 & $100.0 \%$ \\
\hline & & & & & & & & 2 & & 4 & \\
\hline & $\mathrm{D}$ & 0 & $0.0 \%$ & 0 & $0.0 \%$ & 0 & $0.0 \%$ & 0 & $0.0 \%$ & 0 & $100.0 \%$ \\
\hline
\end{tabular}

Fuente: Matriz de sistematización (E.P)

En la Tabla 3 se muestra que los niños de 9 años con obesidad evidencian erupción completa del incisivo lateral en un $100 \%$ en comparación a los niños con normopeso quienes en un $87.5 \%$ presentan una erupción completa del incisivo lateral. Así, de acuerdo a la prueba estadística, se encontró relación entre el estado nutricional y la cronología de la erupción en el incisivo lateral. Cabe mencionar que tanto el $100 \%$ de niños obesos como de normopeso presentaron una erupción completa del primer molar e incisivo; además, existe erupción incompleta en el primer premolar en un $28.9 \%$ en obesos y $0 \%$ en niños con nutrición normal. De acuerdo a la prueba estadística, se halló la relación existente entre el estado nutricional y la cronología de erupción del primer premolar inferior. En el caso del segundo premolar, el $2.6 \%$ de niños obesos y el $8.3 \%$ de niños con normopeso presentaron erupción completa. Con referencia al segundo molar, se halló que el $2.6 \%$ de obesos presentó erupción incompleta, no encontrándose relación entre sus variables.

Tabla 3. Relación del estado nutricional en la cronología de la erupción de la arcada inferior en estudiantes de 9 años de la Institución Educativa Nacional Gregorio Albarracín

\begin{tabular}{|c|c|c|c|c|c|c|c|c|c|c|c|}
\hline \multirow{2}{*}{$\begin{array}{l}\text { Pza } \\
\text { Dentaria }\end{array}$} & \multirow[t]{2}{*}{ IMC } & \multicolumn{2}{|c|}{ N.E } & \multicolumn{2}{|c|}{ I.E } & \multicolumn{2}{|c|}{ E.I } & \multicolumn{2}{|c|}{ E.C } & \multicolumn{2}{|c|}{ Total } \\
\hline & & $\mathrm{N}$ & $\%$ & $\mathrm{~N}$ & $\%$ & $\mathrm{~N}$ & $\%$ & $\mathrm{~N}$ & $\%$ & $\mathrm{~N}$ & $\%$ \\
\hline \multirow{4}{*}{$\begin{array}{l}\text { Incisivo } \\
\text { Central } \\
\mathrm{P}=(*)\end{array}$} & $\mathrm{N}$ & 0 & $0.0 \%$ & 0 & $0.0 \%$ & 0 & $0.0 \%$ & 2 & $100.0 \%$ & 2 & $100.0 \%$ \\
\hline & & & & & & & & 4 & & 4 & \\
\hline & $\mathrm{O}$ & 0 & $0.0 \%$ & 0 & $0.0 \%$ & 0 & $0.0 \%$ & $\begin{array}{l}3 \\
8\end{array}$ & $100.0 \%$ & $\begin{array}{l}3 \\
8\end{array}$ & $100.0 \%$ \\
\hline & D & 0 & $0.0 \%$ & 0 & $0.0 \%$ & 0 & $0.0 \%$ & 0 & $0.0 \%$ & 0 & $100.0 \%$ \\
\hline \multirow{3}{*}{$\begin{array}{l}\text { Incisivo } \\
\text { Lateral } \\
\mathrm{P}=0.025\end{array}$} & $\mathrm{~N}$ & 0 & $0.0 \%$ & 0 & $0.0 \%$ & 3 & $12.5 \%$ & 21 & $87.5 \%$ & 24 & $100.0 \%$ \\
\hline & $\mathrm{O}$ & 0 & $0.0 \%$ & 0 & $0.0 \%$ & 0 & $0.0 \%$ & 38 & $100.0 \%$ & 38 & $100.0 \%$ \\
\hline & D & 0 & $0.0 \%$ & 0 & $0.0 \%$ & 0 & $0.0 \%$ & 0 & $0.0 \%$ & 0 & $100.0 \%$ \\
\hline
\end{tabular}




\begin{tabular}{|c|c|c|c|c|c|c|c|c|c|c|c|}
\hline \multirow{5}{*}{$\begin{array}{l}\text { Canino } \\
\mathrm{P}=0.122\end{array}$} & $\mathrm{~N}$ & 2 & $83.3 \%$ & 2 & $8.3 \%$ & 2 & $8.3 \%$ & 0 & $0.0 \%$ & 2 & $100.0 \%$ \\
\hline & & 0 & & & & & & & & 4 & \\
\hline & $\mathrm{O}$ & 3 & $81.6 \%$ & 7 & $18.4 \%$ & 0 & $0.0 \%$ & 0 & $0.0 \%$ & 3 & $100.0 \%$ \\
\hline & & 1 & & & & & & & & 8 & \\
\hline & $\mathrm{D}$ & 0 & $0.0 \%$ & 0 & $0.0 \%$ & 0 & $0.0 \%$ & 0 & $0.0 \%$ & 0 & $100.0 \%$ \\
\hline \multirow{4}{*}{$\begin{array}{l}\text { Primer } \\
\text { Premolar } \\
\mathrm{P}=0.002\end{array}$} & $\mathrm{~N}$ & 21 & $87.5 \%$ & 0 & $0.0 \%$ & 0 & $0.0 \%$ & 3 & $12.5 \%$ & 24 & $100.0 \%$ \\
\hline & & & & & & & & & & & \\
\hline & $\mathrm{O}$ & 24 & $63.2 \%$ & 3 & $7.9 \%$ & 11 & $28.9 \%$ & 0 & $0.0 \%$ & 38 & $100.0 \%$ \\
\hline & $\mathrm{D}$ & 0 & $0.0 \%$ & 0 & $0.0 \%$ & 0 & $0.0 \%$ & 0 & $0.0 \%$ & 0 & $100.0 \%$ \\
\hline \multirow{5}{*}{$\begin{array}{l}\text { Segundo } \\
\text { Premolar } \\
\mathrm{P}=0.314\end{array}$} & $\mathrm{~N}$ & 2 & $91.7 \%$ & 0 & $0.0 \%$ & 0 & $0.0 \%$ & 2 & $8.3 \%$ & 2 & $100.0 \%$ \\
\hline & & 2 & & & & & & & & 4 & \\
\hline & $\mathrm{O}$ & 3 & $86.8 \%$ & 1 & $2.6 \%$ & 3 & $7.9 \%$ & 1 & $2.6 \%$ & 3 & $100.0 \%$ \\
\hline & & 3 & & & & & & & & 8 & \\
\hline & $\mathrm{D}$ & 0 & $0.0 \%$ & 0 & $0.0 \%$ & 0 & $0.0 \%$ & 0 & $0.0 \%$ & 0 & $100.0 \%$ \\
\hline \multirow{5}{*}{$\begin{array}{l}\text { Primer } \\
\text { Molar } \\
\mathrm{P}=(*)\end{array}$} & $\mathrm{N}$ & 0 & $0.0 \%$ & 0 & $0.0 \%$ & 0 & $0.0 \%$ & 2 & $100.0 \%$ & 2 & $100.0 \%$ \\
\hline & & & & & & & & 4 & & 4 & \\
\hline & $\mathrm{O}$ & 0 & $0.0 \%$ & 0 & $0.0 \%$ & 0 & $0.0 \%$ & 3 & $100.0 \%$ & 3 & $100.0 \%$ \\
\hline & & & & & & & & 8 & & 8 & \\
\hline & $\mathrm{D}$ & 0 & $0.0 \%$ & 0 & $0.0 \%$ & 0 & $0.0 \%$ & 0 & $0.0 \%$ & 0 & $100.0 \%$ \\
\hline \multirow{5}{*}{$\begin{array}{l}\text { Segundo } \\
\text { Molar } \\
\mathrm{P}=0.423\end{array}$} & $\mathrm{~N}$ & 2 & $100.0 \%$ & 0 & $0.0 \%$ & 0 & $0.0 \%$ & 0 & $0.0 \%$ & 2 & $100.0 \%$ \\
\hline & & 4 & & & & & & & & 4 & \\
\hline & $\mathrm{O}$ & 3 & $97.4 \%$ & 0 & $0.0 \%$ & 1 & $2.6 \%$ & 0 & $0.0 \%$ & 3 & $100.0 \%$ \\
\hline & & 7 & & & & & & & & 8 & \\
\hline & $\mathrm{D}$ & 0 & $0.0 \%$ & 0 & $0.0 \%$ & 0 & $0.0 \%$ & 0 & $0.0 \%$ & 0 & $100.0 \%$ \\
\hline
\end{tabular}

\section{(*= no aplica) $\quad$ Fuente: Matriz de sistematización (E.P)}

En la Tabla 4 se muestra que un $35.2 \%$ de niños de 10 años con obesidad evidenciaron erupción completa del primer premolar en comparación al 27.3 $\%$ de niños con normopeso. De acuerdo a la prueba estadística del chi cuadrado, se halló la relación existente entre el estado nutricional y la cronología de erupción del primer premolar inferior. Cabe mencionar que el $100 \%$ tanto de obesos como de normales presentaron una erupción completa del primer molar e incisivo central; además, $29.6 \%$ en niños obesos y un $27.3 \%$ en niños con nutrición normal presentaron una erupción completa del segundo premolar. Se halló también que el $18.5 \%$ de niños obesos y el $18.2 \%$ de niños normales presentaron erupción completa del canino. Finalmente, solo el $3.7 \%$ de niños obesos representó erupción completa del segundo molar superior en comparación con niños de nutrición normal que no presentaron erupción completa.

\section{Tabla 4. Relación del estado nutricional en la cronología de la erupción de la arcada inferior en estudiantes de 10 años de la Institución Educativa Nacional Gregorio Albarracín}

\begin{tabular}{|c|c|c|c|c|c|c|c|c|c|c|c|}
\hline \multirow[t]{2}{*}{ Pza Dentaria } & \multirow[t]{2}{*}{ IMC } & \multicolumn{2}{|c|}{ N.E } & \multicolumn{2}{|c|}{ I.E } & \multicolumn{2}{|c|}{ E.I } & \multicolumn{2}{|c|}{ E.C } & \multicolumn{2}{|c|}{ TOTAL } \\
\hline & & $\mathrm{n}$ & $\%$ & $\mathrm{n}$ & $\%$ & $\mathrm{n}$ & $\%$ & $\mathrm{n}$ & $\%$ & $\mathrm{n}$ & $\%$ \\
\hline Incisivo & $\mathrm{N}$ & 0 & $0.0 \%$ & 0 & $0.0 \%$ & 0 & $0.0 \%$ & 2 & $100.0 \%$ & 2 & $100.0 \%$ \\
\hline Central & & & & & & & & 2 & & 2 & \\
\hline $\mathrm{P}=(*)$ & $\mathrm{O}$ & 0 & $0.0 \%$ & 0 & $0.0 \%$ & 0 & $0.0 \%$ & 5 & $100.0 \%$ & 5 & $100.0 \%$ \\
\hline & & & & & & & & 4 & & 4 & \\
\hline & $\mathrm{D}$ & 0 & $0.0 \%$ & 0 & $0.0 \%$ & 0 & $0.0 \%$ & 0 & $0.0 \%$ & 0 & $100.0 \%$ \\
\hline
\end{tabular}




\begin{tabular}{|c|c|c|c|c|c|c|c|c|c|c|c|}
\hline \multirow{3}{*}{$\begin{array}{l}\text { Incisivo } \\
\text { Lateral } \\
\mathrm{P}=0.521\end{array}$} & $\mathrm{~N}$ & 0 & $0.0 \%$ & 0 & $0.0 \%$ & 0 & $0.0 \%$ & 22 & $100.0 \%$ & 22 & $100.0 \%$ \\
\hline & $\mathrm{O}$ & 1 & $1.9 \%$ & 0 & $0.0 \%$ & 0 & $0.0 \%$ & 53 & $98.1 \%$ & 54 & $100.0 \%$ \\
\hline & $\mathrm{D}$ & 0 & $0.0 \%$ & 0 & $0.0 \%$ & 0 & $0.0 \%$ & 0 & $0.0 \%$ & 0 & $100.0 \%$ \\
\hline \multirow{5}{*}{$\begin{array}{l}\text { Canino } \\
\mathrm{P}=0.570\end{array}$} & $\mathrm{~N}$ & 1 & $45.5 \%$ & 0 & $0.0 \%$ & 4 & $36.4 \%$ & 4 & $18.2 \%$ & 2 & $100.0 \%$ \\
\hline & & 0 & & & & & & & & 2 & \\
\hline & $\mathrm{O}$ & 2 & $46.3 \%$ & 4 & $7.4 \%$ & 1 & $27.8 \%$ & 1 & $18.5 \%$ & 5 & $100.0 \%$ \\
\hline & & 5 & & & & 5 & & 0 & & 4 & \\
\hline & $\mathrm{D}$ & 0 & $0.0 \%$ & 0 & $0.0 \%$ & 0 & $0.0 \%$ & 0 & $0.0 \%$ & 0 & $100.0 \%$ \\
\hline \multirow{4}{*}{$\begin{array}{l}\text { Primer } \\
\text { Premolar } \\
\mathrm{P}=0.032\end{array}$} & $\mathrm{~N}$ & 11 & $50.0 \%$ & 3 & $13.6 \%$ & 2 & $9.1 \%$ & 6 & $27.3 \%$ & 22 & $100.0 \%$ \\
\hline & & & & & & & & & & & \\
\hline & $\mathrm{O}$ & 10 & $18.5 \%$ & 9 & $16.7 \%$ & 16 & $29.6 \%$ & 19 & $35.2 \%$ & 54 & $100.0 \%$ \\
\hline & $\mathrm{D}$ & 0 & $0.0 \%$ & 0 & $0.0 \%$ & 0 & $0.0 \%$ & 0 & $0.0 \%$ & 0 & $100.0 \%$ \\
\hline \multirow{5}{*}{$\begin{array}{l}\text { Segundo } \\
\text { Premolar } \\
\mathrm{P}=0.683\end{array}$} & $\mathrm{~N}$ & 1 & $54.5 \%$ & 0 & $0.0 \%$ & 4 & $18.2 \%$ & 6 & $27.3 \%$ & 2 & $100.0 \%$ \\
\hline & & 2 & & & & & & & & 2 & \\
\hline & $\mathrm{O}$ & 2 & $44.4 \%$ & 0 & $0.0 \%$ & 1 & $25.9 \%$ & 1 & $29.6 \%$ & 5 & $100.0 \%$ \\
\hline & & 4 & & & & 4 & & 6 & & 4 & \\
\hline & $\mathrm{D}$ & 0 & $0.0 \%$ & 0 & $0.0 \%$ & 0 & $0.0 \%$ & 0 & $0.0 \%$ & 0 & $100.0 \%$ \\
\hline \multirow{5}{*}{$\begin{array}{l}\text { Primer } \\
\text { Molar } \\
\mathrm{P}=(*)\end{array}$} & $\mathrm{N}$ & 0 & $0.0 \%$ & 0 & $0.0 \%$ & 0 & $0.0 \%$ & 2 & $100.0 \%$ & 2 & $100.0 \%$ \\
\hline & & & & & & & & 2 & & 2 & \\
\hline & $\mathrm{O}$ & 0 & $0.0 \%$ & 0 & $0.0 \%$ & 0 & $0.0 \%$ & 5 & $100.0 \%$ & 5 & $100.0 \%$ \\
\hline & & & & & & & & 4 & & 4 & \\
\hline & $\mathrm{D}$ & 0 & $0.0 \%$ & 0 & $0.0 \%$ & 0 & $0.0 \%$ & 0 & $0.0 \%$ & 0 & $100.0 \%$ \\
\hline \multirow{5}{*}{$\begin{array}{l}\text { Segundo } \\
\text { Molar } \\
\mathrm{P}=0.468\end{array}$} & $\mathrm{~N}$ & 1 & $63.6 \%$ & 2 & $9.1 \%$ & 6 & $27.3 \%$ & 0 & $0.0 \%$ & 2 & $100.0 \%$ \\
\hline & & 4 & & & & & & & & 2 & \\
\hline & $\mathrm{O}$ & 3 & $66.7 \%$ & 8 & $14.8 \%$ & 8 & $14.8 \%$ & 2 & $3.7 \%$ & 5 & $100.0 \%$ \\
\hline & & 6 & & & & & & & & 4 & \\
\hline & $\mathrm{D}$ & 0 & $0.0 \%$ & 0 & $0.0 \%$ & 0 & $0.0 \%$ & 0 & $0.0 \%$ & 0 & $100.0 \%$ \\
\hline
\end{tabular}

$(*=$ no aplica $)$

Fuente: Matriz de sistematización (E.P)

\section{Discusión}

El presente estudio encontró relación existente entre el estado nutricional y la erupción del primer molar inferior, el primer premolar inferior y el incisivo lateral inferior en niños de 8,9 y 10 años respectivamente que presentaron estado nutricional de obesidad. Según esta aseveración, el estado nutricional en condición de obeso tendría relación con la erupción precoz de dichas piezas dentarias. Contrastando este trabajo con el estudio realizado por Flores Calizaya (15) ejecutado en el distrito de Ciudad Nueva 2013 en la que halló retraso en la erupción del incisivo central superior en niños de ambos sexos con 7 años y retraso en la erupción del primer premolar inferior en niños de 11 años con desnutrición, se puede interpretar que los niños con estado nutricional en condición de desnutrición tienen un retraso en la erupción dentaria; muy por el contrario, se observa adelanto de la erupción dentaria en niños que presentan un estado nutricional de obesidad. Además, el estudio mencionado encontró un porcentaje menor de obesidad y de desnutrición, mientras que en nuestro estudio predominó la obesidad seguido de normopesos, esto puede ser debido a la influencia de muchos factores, tales como el nivel socioeconómico, cultural, etc. Es importante mencionar que la institución estudiada recibe el Qali warma (alimentación escolar), esto corrobora los datos estadísticos que señalan la mayor prevalencia en obesidad y sobrepeso en la ciudad de Tacna según INS 2016.

Otros investigadores también concuerdan con nuestra estudio, tales como Sacta Quilambaqui Milton (21) cuya muestra estuvo conformada por 164 estudiantes, quien a través de una evaluación antropométrica IMC e intraoral, obtuvo que existe retraso en la erupción dental en los incisivos y molares permanente en niños con desnutrición y riesgo a desnutrición, y erupción precoz de los incisivos 11 y 21 y los primeros molares permanentes en niños/a con 
obesidad o riesgo de obesidad. De igual forma, Esther Vaillard Jiménez (22) estudió a 3.519 niños de entre cero meses hasta 14 años 11 meses; la autora concluyó que la erupción dental se debe considerar como parte del crecimiento y desarrollo, además, que existe una correlación positiva verdadera entre el peso y la estatura con la erupción dental. Esta información demuestra la relación existente del estado nutricional y la cronología de la erupción. En el caso específico de Tacna, sabemos que tenemos una alta prevalencia de obesidad infantil, por lo que la presencia de obesidad está influenciando en la erupción precoz de la dentición permanente en la población estudiada, siendo trascendente esta información en el campo de la ortodoncia y ortopedia maxilar, para un determinado estudio en el diagnóstico del paciente.

Esta investigación nos proporciona hallazgos que son aplicables a la población estudiada, por lo tanto, supone limitaciones; así, existe la necesidad de realizar estudios regionales mayores que caractericen a ambos sexos e involucren la diversidad étnica de nuestra ciudad.

\section{Conclusiones}

Existe relación entre el estado nutricional y la cronología de erupción en dentición permanente incluyendo el primer molar inferior, el primer premolar inferior y el incisivo lateral inferior con erupción acelerada en niños con elevado IMC, mientras que en las demás piezas dentarias no se evidenció influencia significativa desde el punto de vista estadístico.

En la población estudiada predomina la obesidad seguida de normopeso.

La cronología de la erupción dentaria en la arcada superior e inferior de nuestra población estudiada se encuentra adelantada (0.4 meses) con respecto al índice de Logan y Kronfeld.

\section{Recomendaciones}

Incorporar en las historias odontológicas y de ortodoncia el registro de índice de masa corporal (IMC) y valorar esta referencia en niños con dentición permanente.

Elaborar programas de control de los desórdenes del estado nutricional que sean planificados y dirigidos a los estudiantes, profesores, y padres de familia con el fin de controlar las cifras altas de obesidad y evitar complicaciones posteriores, dirigidas por instituciones educativas y de salud pública, siendo las escuelas de ciencias de la salud de las universidades parte de este objetivo.

Capacitación para docentes y personal que labora en instituciones educativas sobre conocimientos básicos de hábitos saludables en dieta y nutrición, proponiendo el consumo de alimentos nutritivos.

\section{Referencias bibliográficas}

1.-Organización Mundial de la Salud. National Health Statistics Center. Estudios NHANES I, II. Fels Research Institute (FRI). Centro Nacional de Alimentación y Nutrición; 2000.

2- Strauss R. Childhood Obesity. Current Problems in $\mathrm{P}$ e d i a t r i c s $1999 ; 29: 5-29$.

3.- Himes J, Dietz W. Guidelines for overweight in adolescent preventive services:recommendations from an expert committee, The American Journal of Clinical Nutrition, [Publicación

periódica en línea] 1994. Feb [cited 2016 Jun 5]; 59(2 ): [307-316 p.] Available from:

https://doi.org/10.1093/ajen/59.2.307

4.- Neeley W.W, Gonzales D.A. (2007) Obesity in adolescence: Implications in orthodontic treatment. Am J Orthod Dentofac Orthop. 131(5):581-588.

5.-Russell D.L., Keil M.F., Bonat S.H., Uwaifo G.I., Nicholson J.C., McDuffie J.C., Hill S.C., Yanovski
J.A.,(2001) The relation between skeletal maturation and adiposity in African American and Caucasian children. J Pediatr. 139(6):844-848.

6.-Legiran S., Brandi M.L. (2012) Bone mass regulation of leptin and postmenopausal osteoporosis with obesity.Clin Cases Miner Bone Metab.9 (3):145149.

7.- Gómez ME, Campos A. Histología y embriología bucodental. 2a ed. Madrid: Panamericana; 2006.

8.- Barbería E. Erupción Dentaria: Tratamiento y prevención de sus alteraciones. Pediatr Integral [Internet]. 2001 [Citado 14 de febrero 2014]; 6(3):229$240 . \quad$ D i s p o n i b l e e n : http://issuu.com/jes0889/docs/erupcion_dentaria/1

9.- Djurisic A, Alcedo C, González F, Quirós O, Farías $\mathrm{M}$, Rondón $\mathrm{S}$, et al. Alteración de la secuencia de erupción entre canino y primer premolar en el maxilar inferior en pacientes de la Facultad de Odontología de la UGMA con edades comprendidas entre 9 y 11 años. Rev Latinoam Ortod Odontopediatr [Internet]. 2007 [citado 
10 de marzo 2014 ]. Disponible en: http://www.ortodoncia.ws/publicaciones/2007/alteraci on.secuencia.erupcion.asp

10.- Heinrich-Weltzien R, Zorn C, Monse B, KromeyerHauschild K. Relationship between malnutrition and the number of permanent teeth in Filipino 10 to 13 year olds. Biomed Res Int. [Internet]. 2013 Agost. [Citado 20 f e b r e r o 201014 ]. D is p o n i b l e e n : http://www.ncbi.nlm.nih.gov/pmc/articles/PMC37733 87

11.- Salzmann JA. Practice of Orthodontics. Philadelphia: Lippincott Company; 1966.pp.501, 751, 758.

12.- Palmaert M, Radovick S, Boeggle P. Leptin levels in childrenwith central precocious puberty. J Clin Endocrinol Metab 1998; 83:2260-2265.

13.- Canut JA. Ortodoncia Clínica y Terapéutica. 2 ed. Barcelona: Masson; 2000.pp. 26-30

14.- Rojas M. Guillèn F, Comparación de la maduración ósea en pre púberes y adolescentes y su aplicación en el tratamiento ortopédico Mandibular. Revista estomatológica Altiplano 2014; (2):9-14

15.- Flores, C. Influencia del Estado Nutricional en la Erupción Dentaria Permanente en Estudiantes del Nivel Primario del Distrito de Ciudad Nueva-Tacna 2012 [Tesis para optar el grado de Cirujano Dentista]. Tacna: Universidad Nacional Jorge Basadre Grohmann ; 2012.

16.- Akridge M, Hilgers Kelly K., Silveira Anibal M, Scarfe W, Scheetz James P, and Kinane Danis F. fLouisville, Ky, and Goodyear Ariz. Childhood obesity and skeletal maturation assessed with Fishman's hand- wrist analysis.The American Association of Orthodontists.2007.

17.- Paredes ,G.K,Pava Rengifo N.Y .Estado Nutricional Actual y Erupcion Dentaria de los Incisivos Permanentes en alumnos de 6 a 9 años de La I.E.P.S.M. "61004" [Tesis para optar el grado de Cirujano Dentista] Iquitos: Universidad Nacional de la Amazonía Peruana; 2014.

18. -Bath-Balog M, Fehrenbach MJ. Dental Embryology, Histology and Anatomy. 2a ed. St. Louis: Elsevier; 2006.

19.- Gorski JP, Marks J. Current concepts of the biology of tooth eruption. Rev. Oral Biol. Med. 1992; 3(3):185206.

20.-Instituto Nacional de Salud - Centro Nacional de Alimentación y Nutrición. Módulo: Medidas Antropométricas Registro y Estandarización. Lima: Instituto Nacional de Salud; 1998.

21.-Moya S, Tamara J, Sacta M. Influencia del estado nutricional en la erupción dentaria de los primeros incisivos y molares permanentes en estudiantes de 5 a 7 años en la escuela de Provincia de Oro -Ayora Cayambe." [Tesis para optar el grado de Odontólogo]. Ecuador: Universidad Central de Ecuador; 2015.

22.- Vaillard Jimènez Esther, Castro Bernal Concepción,Carrasco Gutierrez RosandoEspinoza de Santillana Irene,Lezama Flores Gloria,\& Meléndez Ocampo Argelia. Correlación de peso y estatura con erupción dental. Rev Cubana Estomatol. 20018 Mar [citado 2016 Ago 1 ]; 45(1) Disponible en shorturl.at/dBIXY
Correspondencia:

milsonrisas1000@hotmail.com
Fecha de recepción : 15 de agosto de 2019

Fecha de aceptación : 19 de noviembre de 2019 